\title{
Limitations of the Conventional Phase Advance Method for Constant Power Operation of the Brushless DC Motor
}

\author{
J. S. Lawler \\ University of Tennessee \\ Knoxville, Tennessee
}

\author{
J. M. Bailey and John W. McKeever \\ Oak Ridge National Laboratory \\ Oak Ridge, Tennessee
}

\author{
João Pinto \\ Universidade Federal \\ de Matto Grosso do Sul \\ Brazil
}

\begin{abstract}
The brushless dc motor (BDCM) has high-power density and efficiency relative to other motor types. These properties make the BDCM well suited for applications in electric vehicles provided a method can be developed for driving the motor over the 4 to $6: 1$ constant power speed range (CPSR) required by such applications. The present state of the art for constant power operation of the BDCM is conventional phase advance (CPA) [1]. In this paper, we identify key limitations of CPA. It is shown that the CPA has effective control over the developed power but that the current magnitude is relatively insensitive to power output and is inversely proportional to motor inductance. If the motor inductance is low, then the rms current at rated power and high speed may be several times larger than the current rating. The inductance required to maintain rms current within rating is derived analytically and is found to be large relative to that of BDCM designs using high-strength rare earth magnets. Thus, the CPA requires a BDCM with a large equivalent inductance.
\end{abstract}

\section{INTRODUCTION}

The size, weight, and efficiency properties of the BDCM are highly desirable in electric vehicle applications. However, such applications also require a broad CPSR such as 4 to 6:1. The present state of the art for driving a BDCM beyond base speed is CPA [1]. In this paper, several important limitations of the CPA method are identified.

Specifically, CPA requires that the equivalent motor inductance per phase be sufficiently large. If the motor inductance is too low, the motor current will exceed its rated value when operating at rated power and high speed. Additional cooling would be required for the motor and inverter, and the semiconductor ratings would have to be increased accordingly. This is unfortunate since high-power-density BDCMs built with rare earth magnets generally have low inductance. A fundamental frequency model of the BDCM driven by CPA is used to quantify the minimum required inductance. Detailed inverter/motor simulation confirms the validity of the simplified fundamental frequency model. It is also shown that the motor current under coasting conditions is not significantly smaller than the motor current at rated power. Consequently, the copper losses in the motor are almost independent of the developed power.

In addition, the CPA uses the conventional voltage fed inverter, which when combined with a permanent magnet motor, has some failure modes that may not be acceptable in electric vehicle applications. If a short circuit occurs in the dc supply, then the motor will supply current to the fault so long as the permanent magnet rotor continues to rotate. Fuses or other protection would need to be included to guard against such faults. In addition, when transistor-firing signals are lost, because of a controller board failure for example, the motor can enter deep regenerative braking when operating at high speed. Not

\footnotetext{
* Prepared by Oak Ridge National Laboratory, managed by UT-Battelle, LLC, for the U.S. Department of Energy under contract DE-AC05-00OR22725.

The submitted manuscript has been authored by a contractor of the U.S. Government under contract DE-AC05-00OR22725.

Accordingly, the U.S. Government retains a nonexclusive, royalty-free license to publish or reproduce the published form of this contribution, or allow others to do so, for U.S. Government purposes.
} 
only would this be confusing to the vehicle operator but it could also create a traffic hazard. Unless the controller board failure automatically activates the brake lights, trailing traffic would not be alerted to the rapid deceleration of the vehicle. To preclude the undesired regeneration, one might open the dc bus. If this were the case, the inverter transistors would experience voltage levels determined by the back emf of the motor. At high speed, the back emf might have a magnitude several times larger than the dc supply voltage and therefore the transistors would need to be rated accordingly.

In Section 2, we present the inverter topology and transistor-firing scheme for high-speed operation of the BDCM by CPA. The parameters of an example motor used throughout the paper are also given. Section 3 provides simulation results for the example motor operating at rated power at three and six times base speed. The example motor is a "low" inductance motor, and the current at high speed is twice the rated value. It is shown that the motor operation in each phase is a mixture of motoring and regenerative braking. The braking action is caused by the conduction of the bypass diodes. For low-inductance motors, the mixture of motoring and regeneration is extreme. A large motoring component is substantially cancelled by a braking component of nearly the same magnitude, leaving a modest net motoring component. Section 4 presents a simple fundamental frequency model that accurately predicts the rms motor current and average motor power developed under high-speed conditions. This model is used to derive a formula for the minimum inductance required by CPA to keep the motor within the rms rating over the desired CPSR. Finally, Section 5 contains our conclusions.

\section{INVERTER TOPOLOGY AND FIRING SCHEME}

The CPA method uses the common three-phase, voltage-fed inverter (VFI) topology shown in Fig. 1. Figure 1 also shows the motor model used for simulation.

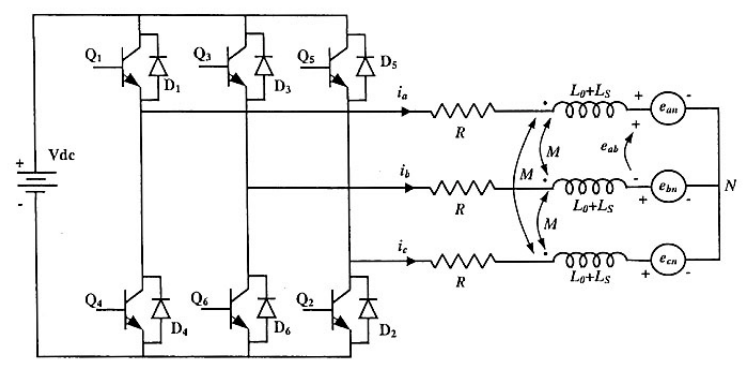

Fig. 1. Common voltage-fed inverter topology and motor model used with conventional phase advance.

The bypass diodes of the common VFI make this configuration inherently capable of regeneration. This capability is desirable in the case of controlled regenerative braking, but it also has two undesirable consequences. If a fault develops in the dc supply, the motor will feed current into the fault so long as the permanent magnets continue to rotate. In addition, if the motor is operating at high speed, a loss of transistor firing signals will result in uncontrolled regenerative braking until the motor slows to the speed where the back emf magnitude drops below the level of the dc supply voltage. Guarding against the consequences of such failures would require additional components.

The phase-to-neutral back emf waveforms of the BDCM are trapezoidal in shape with $120^{\circ}$ of flat top and $60^{\circ}$ of transition in each half cycle, as shown in Fig. 2. The magnitude of the trapezoidal emf increases linearly with speed. Below base speed the BDCM operates in a current regulation mode. The conduction of the transistors is modulated so that while the phase-to-neutral emf is in the "flat-top" portion of each half cycle, the phase current is maintained within a hysteresis band about a current set point. The current 
set point is selected to produce the torque necessary to maintain speed. This type of operation is well understood and is therefore not discussed further here. By definition, base speed is the highest speed at which rated torque can be developed without using phase advance. This speed is slightly less than the speed at which the peak magnitude of the line-to-line emf equals the dc supply voltage. At base speed the dc supply voltage equals the line-to-line emf magnitude plus a small additional amount of voltage necessary to overcome the winding resistance and inductance.
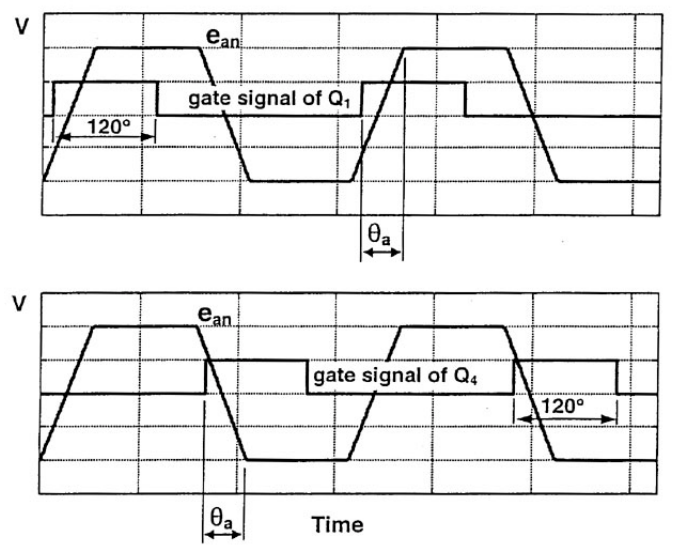

Fig. 2. Transistor firing scheme in phase A.

Above base speed, the back emf exceeds the dc supply voltage and the firing must be advanced (i.e., a phase is energized during the transition portion of the back emf where the available dc supply voltage can drive current into the motor). In the vicinity of base speed, operation is a mixture of phase advance and current regulation. At a speed only slightly greater than base speed, the current regulation becomes ineffective and all the control is accomplished by phase advance. In this work we consider only speeds at which all control is achieved through phase advance.

The firing scheme for the CPA method at high speed is shown in Fig. 2, which indicates the timing of the phase A transistor (Q1 and Q4) gate signals relative to the trapezoidal line-to-neutral back emf, $\mathrm{e}_{\mathrm{an}}$. The phase $\mathrm{B}$ and $\mathrm{C}$ back emfs have the same shape but are delayed from phase A by $120^{\circ}$ and $240^{\circ}$, respectively. The firing of phase $\mathrm{B}$ and $\mathrm{C}$ transistors is analogous to that in Fig. 2 but with the appropriate delays applied. Note that the switching frequency during pure phase advance is at the fundamental electrical frequency consistent with motor speed. Pulse width modulation is not necessary.

Transistor Q1 is fired $\theta_{\mathrm{a}}$ degrees ahead of the instant that the phase A back emf, $\mathrm{e}_{\mathrm{an}}$, reaches its positive maximum. $\theta_{\mathrm{a}}$ is called the "advance angle." Transistor Q4 is fired $\theta_{\mathrm{a}}$ degrees ahead of the instant that $\mathrm{e}_{\mathrm{an}}$ reaches its most negative value. The magnitude of the emf trapezoid increases linearly with speed, but the shape is the same in each cycle. Figure 2 suggests that the gate pulse width of each transistor is $120^{\circ}$, consistent with [1], but we have found that high-speed performance can be improved by increasing the width to nearly $180^{\circ}$. Although [1] indicates that $\theta_{\text {a }}$ can be varied from 0 to $60^{\circ}$, we have found that the limiting range is from -60 to $+120^{\circ}$. An advance angle near $30^{\circ}$, the exact value being parameter and speed dependent, results in zero average power. An advance less than this value results in regenerative braking and a greater value results in motoring operation.

A motor, designed by Oak Ridge National Laboratory (ORNL), is used for illustration. This motor is an axial gap BDCM with samarium-cobalt magnets. The parameters of the motor are as follows: 


$$
\begin{aligned}
\mathrm{p} & =\text { number of poles }=12 \\
\mathrm{~N}_{\mathrm{b}} & =\text { base speed in } \mathrm{rpm}=2600 \mathrm{rpm} \\
\mathrm{N} & =\text { rotor speed in } \mathrm{rpm} \\
\mathrm{n} & =\text { relative speed }=\frac{\mathrm{N}}{\mathrm{N}_{\mathrm{b}}} \\
\Omega_{\mathrm{b}} & =\text { base speed in electrical rad } / \mathrm{sec} \\
& =\frac{\mathrm{p}}{2} \frac{2 \pi \mathrm{N}_{\mathrm{b}}}{60}=1633.6 \text { elec rad } / \mathrm{sec} \\
\mathrm{L}_{\mathrm{o}}+\mathrm{L}_{\mathrm{s}} & =\text { leakage plus self inductance } \\
& =61.8 \mu \mathrm{H} \text { per phase } \\
\mathrm{M} & =\text { mutual inductance } \\
& =11.8 \mu \mathrm{H} \\
\mathrm{L} & =\text { equivalent inductance } \\
& =\mathrm{L}_{\mathrm{o}}+\mathrm{L}_{\mathrm{s}}+\mathrm{M}=73.6 \mu \mathrm{H} \text { per phase } \\
\mathrm{R} & =0.0118 \text { ohms } \\
\mathrm{E}_{\mathrm{b}} & =\text { peak phase-to-neutral back emf at base speed } \\
& =74.16 \text { volts } \\
\mathrm{E}_{\mathrm{n}} & =\text { peak phase-to-neutral back emf at relative speed } \mathrm{n} \\
& =\mathrm{n} \mathrm{E}_{\mathrm{b}} \\
\mathrm{P}_{\mathrm{r}} & =\text { rated power }=36,927 \text { watts }(49.5 \text { horsepower }) \\
\mathrm{T}_{\mathrm{r}} & =\text { rated torque }=135.6 \mathrm{Nm} \\
\mathrm{V}_{\mathrm{dc}} & =\text { dc supply voltage }=188.7 \text { volts }
\end{aligned}
$$

The 188.7-V supply is the voltage required by the motor. Any voltage drop in the inverter would have to be added to this value. In this paper, the inverter voltage drops are neglected and the above ideal value is used.

Assuming the classical idealized rectangular phase current waveshape of the BDCM that typifies operation below base speed (rectangular shape of $120^{\circ}$ duration each half cycle), the theoretical peak and rms currents of this motor are

$$
\begin{aligned}
& \mathrm{I}_{\mathrm{pk}}=\text { peak current }=\frac{\mathrm{P}_{\mathrm{r}}}{2 \mathrm{E}_{\mathrm{b}}}=249 \mathrm{amps} \\
& \mathrm{I}_{\mathrm{rms}}=\sqrt{\frac{2}{3}} \mathrm{I}_{\mathrm{pk}}=203.3 \mathrm{amps} .
\end{aligned}
$$

This motor was used in the laboratory demonstration testing reported in [2,3]. The motor was not designed to be operated beyond $3000 \mathrm{rpm}$. Here, however, we address high-speed performance and will simulate the performance at speeds up to six times the base speed of $2600 \mathrm{rpm}$.

Models in MATLAB and PSPICE were developed to simulate the performance of the BDCM being driven by the CPA control method. The simulators include detailed representation of the motor and switching logic, and the actions of inverter transistors and bypass diodes. To concentrate on performance limitations imposed solely by the CPA method, all loss mechanisms except winding resistance are neglected. Speed-dependent losses such as the core losses (hysteresis and eddy currents), and rotational 
losses (friction and windage) are neglected. Inverter transistors and bypass diodes are modeled as ideal devices. In the next section, simulations at relative speeds of three and six times base speed are presented for operation at rated power.

\section{PERFORMANCE AT THREE AND SIX TIMES BASE SPEED}

For the example motor with a base speed of $2600 \mathrm{rpm}$, relative speeds of $\mathrm{n}=3$ and 6 correspond to 7800 and 15,600 rpm, respectively. Simulation of the motor phase currents and the instantaneous total threephase power over one fundamental electrical cycle are shown in Fig. 3 for operating at rated power of $36,927 \mathrm{~W}$ at relative speeds of 3 and 6 . The advance angle, $\theta_{\mathrm{a}}$, required to achieve rated power is $48.2^{\circ}$ at $\mathrm{n}=3$ and $49.1^{\circ}$ at $\mathrm{n}=6$.
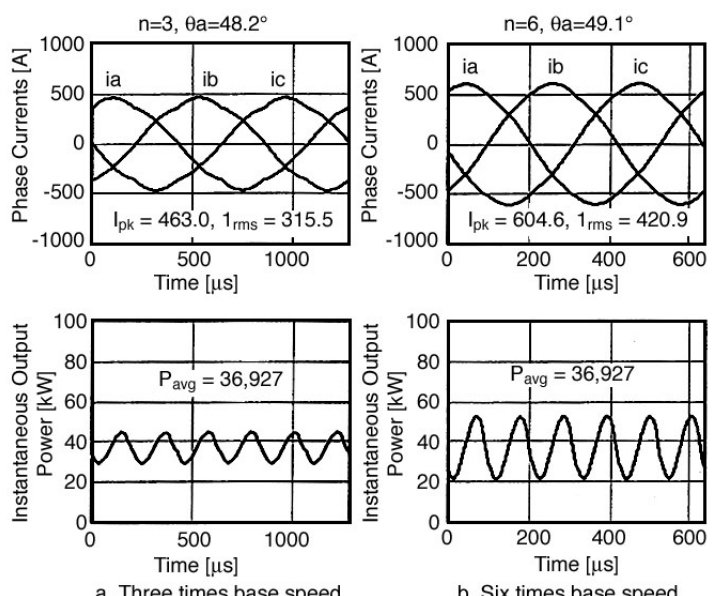

Fig. 3. Motor phase currents at rated power.

Note that the average power is the rated value of $36,927 \mathrm{~W}$ for both operating conditions. The instantaneous power is not smooth but includes ripple that increases in magnitude with speed. In an electric vehicle, this ripple would not be objectionable since it would be filtered by the substantial mass of the vehicle being propelled. However, note that the rms values of the motor phase currents are $315.5 \mathrm{~A}$ and 420.9 A, respectively, for $n=3$ and $n=6$. The rated rms current is only $203.3 \mathrm{~A}$ for this motor. Thus, the rms current increases with speed, and in this case the rms current at full power and at six times base speed is more than twice as large as the rated value.

Insight into the large current when operating above base speed can be seen in Figs. 4 and 5. These figures provide additional detail of the operating condition at six times base speed while motoring at rated power. Figure 4 top shows the phase A motor current and phase-to-neutral back emf. In addition, the portions of phase A current flowing through the phase A transistors (Q1 and Q4) and phase A bypass diodes (D1 and D4) are shown. Observe that when the bypass diodes conduct, the motor phase current and back emf are of opposite sign. Consequently, bypass diode conduction introduces a braking component. Other than a short period of time, introduced by the phase advance, the motor phase current and back emf are of the same sign during transistor conduction. This indicates that transistor conduction contributes motoring power. These conclusions are further supported in Fig. 5. Figure 5 shows the instantaneous values of total power, the power in phase A, the power flowing through the phase A transistors, and the power through the phase A bypass diodes. Observe that although the total power has an average value of $36,927 \mathrm{~W}$ and modest ripple, the instantaneous power in phase A has substantial ripple, more than 400 $\mathrm{kW}$ peak-to-peak and an average value of $12,310 \mathrm{~W}$. The average power flowing through the phase A 
transistors is $60,775 \mathrm{~W}$ of motoring power, while the average power flowing through the phase A bypass diodes is $48,467 \mathrm{~W}$ of braking power. The braking power associated with the bypass diode conduction cancels a like amount of motoring power associated with transistor conduction, leaving the net contribution of phase A as $12.3 \mathrm{~kW}$ of motoring power. Phases $\mathrm{B}$ and $\mathrm{C}$ would exhibit similar behavior, and each phase would contribute, on the average, $12.3 \mathrm{~kW}$, which is one third of the average total power.

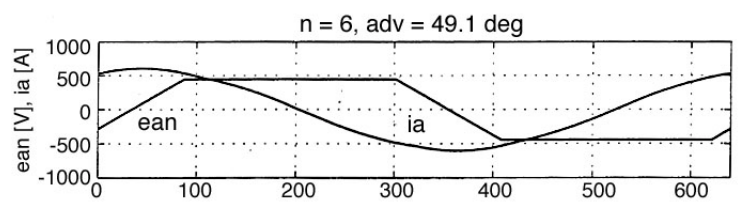

a. Motor current and back emf
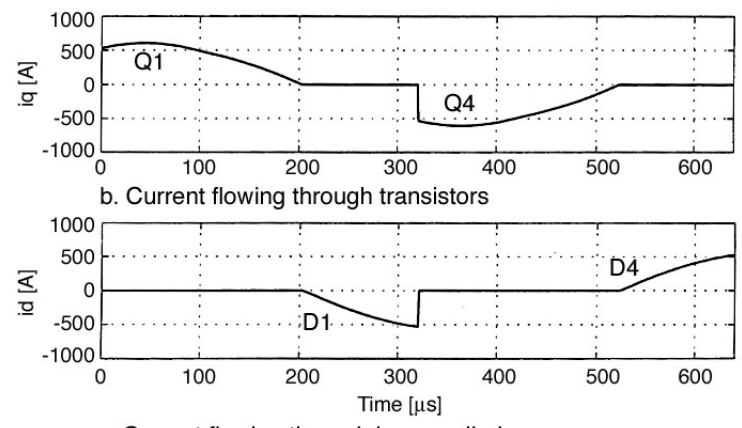

c. Current flowing through bypass diodes

Fig. 4. Phase A current through transistors for $\mathrm{n}=6$ and $\theta_{\mathrm{a}}=\mathbf{4 9 . 1}^{\circ}$.

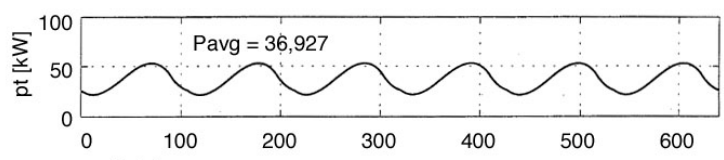

a. Total power

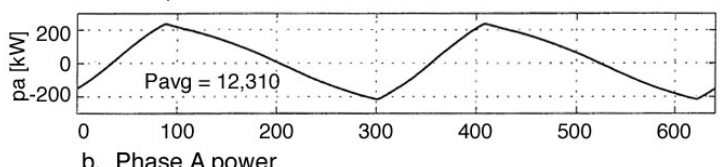

b. Phase A power
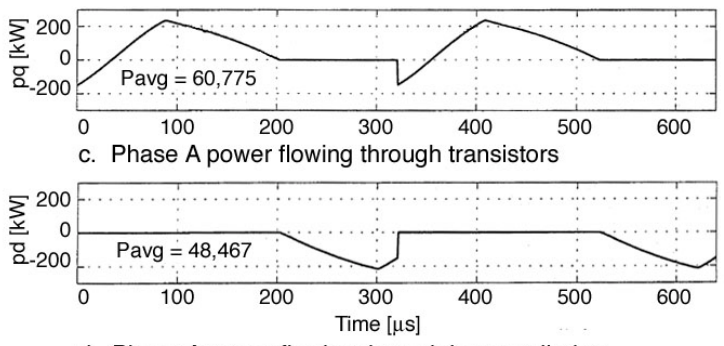

d. Phase A power flowing through bypass diodes

Fig. 5. Instantaneous power waveforms.

The simulation results show that the operation in each phase is a mixture of motoring and braking operation at high speed. For a low-inductance motor, such as the example used here, this mixture is extreme and there is substantial cancellation of motoring power by a large braking component. The braking component is caused by bypass diode conduction. This observation suggests that if bypass diode conduction can be inhibited, eliminating the braking component, the remaining current through transistors 
will contribute predominantly motoring power. It is also likely that the magnitude of the transistor current required to produce rated average power will be substantially reduced. This is the basic concept of the Dual Mode Inverter Control method that is described in $[3,4,5]$.

In the next section, a fundamental frequency model is presented that accurately predicts the motor current and power as a function of advance angle when operating at high speed using CPA.

\section{FUNDAMENTAL FREQUENCY MODEL}

Comparing the relative speed cases of $\mathrm{n}=3$ and 6 in Fig. 3, shows that the motor current of the BDCM, when driven by CPA at high speed, is nearly sinusoidal. The higher the speed, the more nearly the phase currents approach a pure sinusoid at the fundamental electrical frequency. Although not displayed, the voltage applied to the motor by the inverter is a "six-step" type waveform, while the motor back emf is trapezoidal as shown in Fig. 2. Using the fundamental frequency components of the applied inverter voltage and the back emf results in the simplified fundamental frequency phasor model shown in Fig. 6.

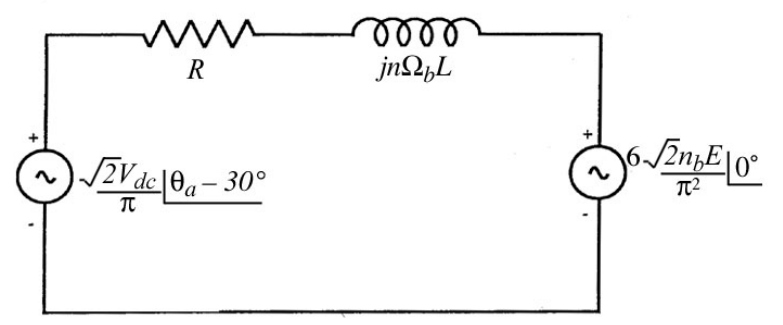

Fig. 6. Per phase of a fundamental frequency CPA phasor model at high speed.

Using this simplified model to analyze the condition $\mathrm{n}=3, \theta_{\mathrm{a}}=48.2^{\circ}$, results in an rms motor current of 315.3 A and an average motor power of $36,378 \mathrm{~W}$. For comparison, the detailed simulator yielded 315.5 $\mathrm{A} \mathrm{rms}$ and $36,927 \mathrm{~W}$ as shown in Fig. 3. For $\mathrm{n}=6, \theta_{\mathrm{a}}=49.1^{\circ}$, the simplified model predicts an rms current of $420.9 \mathrm{~A}$ and an average power of $36,374 \mathrm{~W}$, while the simulator yielded $420.9 \mathrm{~A}$ and $36,927 \mathrm{~W}$. The conclusion is that the simplified model accurately predicts rms current and average motor power.

If the winding resistance is neglected $(\mathrm{R}=0)$, the rms current of the simplified model is given by

$\mathrm{I}_{\mathrm{rms}}=\frac{\sqrt{\frac{2 \mathrm{~V}_{\mathrm{dc}}^{2}}{\mathrm{n}^{2}}+\frac{72 \mathrm{E}_{\mathrm{b}}^{2}}{\pi^{2}}-\frac{24 \mathrm{E}_{\mathrm{b}} \mathrm{V}_{\mathrm{dc}} \cos \left(\theta_{\mathrm{a}}-30^{\circ}\right)}{\mathrm{n} \pi}}}{\pi \Omega_{\mathrm{b}} \mathrm{L}}$

Observe that for a fixed advance angle, $\theta_{\mathrm{a}}$, the rms current varies with the relative speed, $\mathrm{n}$. Equation (3) provides some insight into what is required for CPA to provide an infinite CPSR. Note that as the speed becomes infinite

$\lim _{n \rightarrow \infty} I_{r m s}=\frac{6 \sqrt{2} E_{b}}{\pi^{2} \Omega_{b} L}$. 
For the example motor this limiting value is $530.3 \mathrm{~A}$, which is significantly larger than the $203.3 \mathrm{~A}$ rating of the motor. Consequently, for the example motor, which has an inductance of $73.6 \mu \mathrm{H}$, the CPSR will be finite. In fact, simulation shows that the highest speed at which rated power can be produced without exceeding rated current is $n=1.87$. If the inductance in Eq. (4) were sufficiently large to cause the limiting current value to be 203.3, then the CPA would yield an infinite CPSR. This limiting value of inductance is $192 \mu \mathrm{H}$. A finite CPSR, such as 6:1, will require less than $192 \mu \mathrm{H}$.

A desired, finite CPSR requires an inductance that can be found by setting $\mathrm{n}$ of Eq. (3) equal to the CPSR value and recognizing that to have the rms current remain less than or equal to the rated value, $\mathrm{I}_{\mathrm{b}}$, the inductance must satisfy

$\mathrm{L} \geq \frac{\sqrt{\frac{2 \mathrm{~V}_{\mathrm{dc}}^{2}}{\mathrm{CPSR}^{2}}+\frac{72 \mathrm{E}_{\mathrm{b}}^{2}}{\pi^{2}}-\frac{24 \mathrm{E}_{\mathrm{b}} \mathrm{V}_{\mathrm{dc}}}{\pi \mathrm{CPSR}}}}{\pi \Omega_{\mathrm{b}} \mathrm{I}_{\mathrm{b}}}$.

For the parameters of the example motor, and a CPSR of 6, this expression yields $149 \mu \mathrm{H}$ per phase as the minimum inductance necessary to keep the rms current from exceeding the rated value of $203.3 \mathrm{~A}$ when operating at six times base speed. This value is more than twice the inductance of the example motor.

Figure 7 shows the variation of average motor power and rms current over the full range of advance angle $\left(-60^{\circ} \leq \theta_{\mathrm{a}} \leq 120^{\circ}\right)$, with the nominal motor inductance of $73.6 \mu \mathrm{H}$ at relative speeds of $\mathrm{n}=1.87$ and $\mathrm{n}=6$. Note that the control is effective in swinging the developed power over the full rated range of $36.9 \mathrm{~kW}$ in both the motoring and regenerative braking modes. The plots of power vs advance angle are virtually indistinguishable for the two speeds. Also note that for a given power level substantially more current is required at $n=6$ than for $n=1.87$. A relative speed of 1.87 is the CPSR of this low-inductance motor since it is the highest speed at which a rated power of $36.9 \mathrm{~kW}$ can be produced while maintaining motor current within the rating of 203.3 Arms. At $n=6$, the motor develops the rated power with an rms current of $421 \mathrm{~A}$ as shown in Fig. 7, and in the time domain simulation of Fig. 3. The figure also shows that the rms current is relatively insensitive to advance angle and that the rms current plots are fairly "flat," especially at high speed. Consequently, at zero power the rms motor current is not much smaller than at full power in either the braking or regenerative braking mode. Thus, the copper losses in the motor are decoupled from the power output and the efficiency will be low when coasting. Figure 7 shows that the CPSR of a low-inductance motor is small when driven by CPA. 

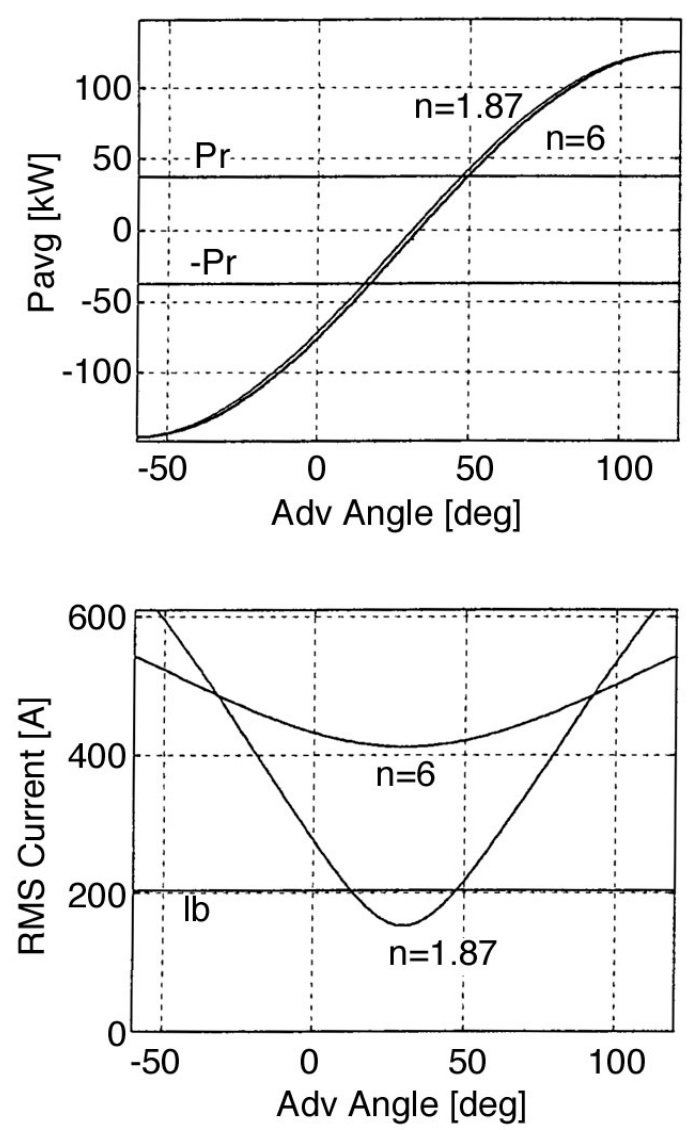

Fig. 7. Average power and rms current vs advance angle with $\mathrm{k}=73.6 \mu \mathrm{H}$.

Figure 8 shows that the CPSR can be extended if the motor inductance is sufficiently large. In this figure, the inductance of the example motor is increased from 73.6 to $149 \mu \mathrm{H}$ per phase with all other parameters held constant. The figure shows rms current and average power vs advance angle for a relative speed of $\mathrm{n}=6$. The inductance value of $149 \mu \mathrm{H}$ was derived previously as the value required for a CPSR of 6:1. However, the formula did not include the effect of winding resistance, which is included in Fig. 8. Note in Fig. 8 that the $36.9 \mathrm{~kW}$ of rated power can be developed with a current that is only slightly larger than the 203.3 A rating of the motor. Thus, if the inductance is sufficiently large, the CPA can drive the BDCM over an extended CPSR. Observe in the comparison of Figs. 7 and 8 that although the higher inductance is effective in bringing the rms current within the machine rating, the peak power that can be developed is reduced. In the low-inductance, 73.6- $\mu \mathrm{H}$ case, the peak power is approximately $120 \mathrm{~kW}$ in the motoring mode and about $150 \mathrm{~kW}$ in the regenerative braking mode, compared with the $36.9-\mathrm{kW}$ rating of the motor. This provides substantial margin for short-term overloads. In the higher inductance, $149-\mu \mathrm{H}$ case, the peak power capability is reduced to approximately $60 \mathrm{~kW}$ in the motoring mode and $70 \mathrm{~kW}$ in the braking mode. Thus, the added inductance reduces the peak power-producing capability of the machine. The reduction in peak power-producing capability can be important in electric vehicle applications where short-term overload is desired for passing or rapid regenerative braking. 

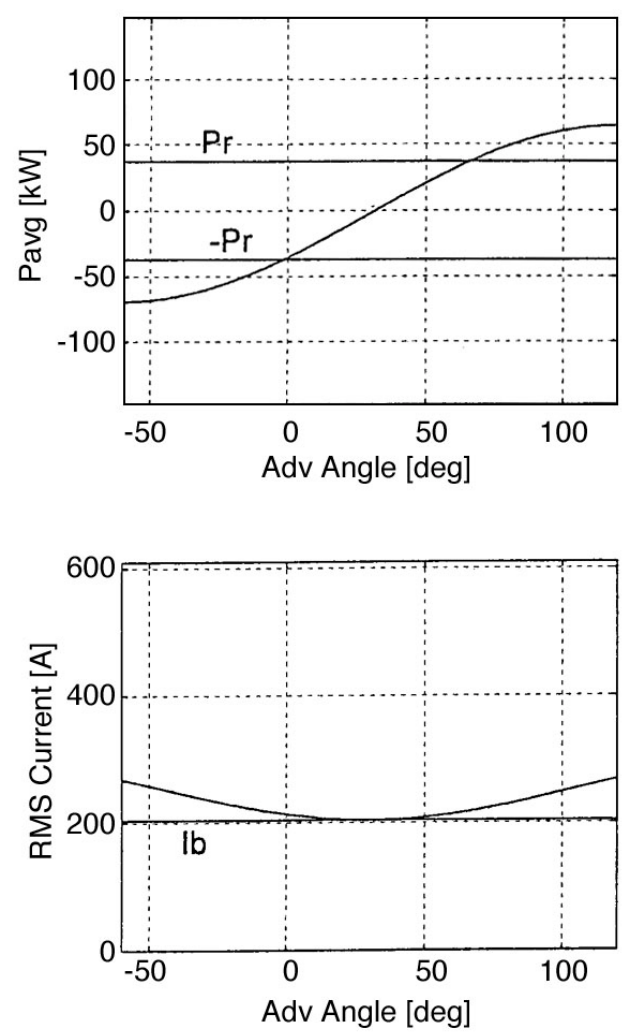

Fig. 8. Average power and rms current vs advance angle for the example motor at $15,600 \mathrm{rpm}$ for $\mathrm{L}=149 \mu \mathrm{H}$.

\section{CONCLUSIONS}

In this paper we have identified several limitations of the CPA method for constant power operation of the BDCM. The CPA is especially sensitive to the motor inductance that must be larger than a threshold value to maintain motor current within rating when operating at rated power at high speed. If the motor inductance is low, additional cooling will be necessary for the motor and inverter components and the current rating of the inverter will have to be increased. High inductance is found to require a higher dc supply voltage and results in a reduction in the peak power production capability of the motor. A fundamental frequency model was developed that allows easy determination of the required inductance.

The CPA uses the common VFI, which has some failure modes that may not be acceptable in electric vehicle applications or that will require the addition of supplementary components to guard against these failures. Specifically, the motor will feed faults that occur in the inverter or dc supply system so long as the permanent magnet rotor continues to revolve. Loss of transistor firing signals when motoring at highspeed results in deep regenerative braking that may create a danger to the vehicle and trailing traffic. Opening the dc bus following such a failure results in the inverter transistors being exposed to the voltage level of the motor back emf, which may be much larger than the dc supply voltage. The transistors may be damaged unless their voltage rating is based on the maximum motor emf rather than the dc supply voltage. 
The highest power density and efficiency BDCMs have inductance that is too low to be compatible with CPA. To realize the full benefit of such motors, an alternative control scheme is required. Keying on the detrimental impacts of bypass diode conduction under CPA, the authors have developed an alternative method of driving the BDCM above base speed. This alternative is called dual-mode inverter control (DMIC) [6]. The DMIC uses thyristors to block the undesired conduction of the bypass diodes at high speed. It has been shown that when all the loss mechanisms are neglected, the BDCM has an infinite CPSR when driven by the DMIC. The thyristors also isolate the motor from faults and avoid undesired regeneration following loss of firing signals. Preliminary studies of the DMIC, including a laboratory demonstration, can be found in $[2,4]$.

\section{REFERENCES}

1. Cambier et al., Brushless DC Motor Using Phase Timing Advancement, U.S. Patent Number 5,677,605, October 14, 1997.

2. J. M. Bailey et al., Dual Mode Inverter Control Test Verification, ORNL/TM-2000/172, Oak Ridge National Laboratory, 2001.

3. J. S. Lawler, J. M. Bailey, J. W. McKeever, and J. Pinto, "Extending the Constant Power Speed Range of the Brushless DC Motor through Dual Mode Inverter Control - Part II: Laboratory Proofof-Principle," submitted to the IEEE Industry Applications Society, $37^{\text {th }}$ Annual Meeting, Pittsburgh, Pennsylvania, October 2002.

4. J. S. Lawler, J. M. Bailey, and J. W. McKeever, Extended Constant Power Speed Range of the Brushless DC Motor through Dual Mode Inverter Control, ORNL/TM-2000/130, Oak Ridge National Laboratory, 2001.

5. J. S. Lawler, J. M. Bailey, J. W. McKeever, and J. Pinto, "Extending the Constant Power Speed Range of the Brushless DC Motor through Dual Mode Inverter Control - Part I: Theory and Simulation," submitted to the IEEE Industry Applications Society, $37^{\text {th }}$ Annual Meeting, Pittsburgh, Pennsylvania, October 2002S.

6. J. S. Lawler and J. M. Bailey, Constant Power Speed Range Extension of Surface Mounted PM Motors, U.S. Patent Number 6,236,179 B1, May 22, 2001. 